\title{
ANL/MSD/CP-100889
}

\section{TWO- AND THREE-DIMENSIONAL ULTRANANOCRYSTALLINE DIAMOND (UNCD) STRUCTURES FOR A HIGH RESOLUTION DIAMOND-BASED MEMS TECHNOLOGY*}

O. Auciello' ${ }^{1}$, A. R. Krauss², D. M. Gruen², H. G. Busmann ${ }^{3}$, E. M. Meyer ${ }^{4}$, , J. Tucek ${ }^{2}$, A. Sumant $^{2}$, A. Jayatissa ${ }^{2}$, N. Moldovan ${ }^{5}$, D. C. Mancini ${ }^{5}$, and M. N. Gardos ${ }^{6}$

${ }^{1}$ Materials Science Division

${ }^{2}$ Chemistry Division

${ }^{3}$ Experimental Facilities Division

Argonne National Laboratory

Argonne, IL 60439

${ }^{4}$ Institute for Microsensors, Actuators, and Systems (IMSAS)

University of Bremen

Bremen, Germany

${ }^{5}$ Fraunhofer Institute for Applied Materials Science (IFAM)

Bremen, Germany

${ }^{6}$ Raytheon Systems Company

2000 El Segundo, CA 90245

December 1999

The submitted manuscript has been created
by the University of Chicago as Operator of
Argonne National Laboratory ("Argonne")
under Contract No. W-31-109.ENG-38 with
the U.S. Department of Energy. The U.S
Government retains for itself, and others
acting on its behalf, a paid-up, non exclusive,
irrevocable worldwide license in said article to
reproduce, prepare derivative works, distribute
copies to the public, and perform publicly and
display publicly, by or on behalf of the
Government.

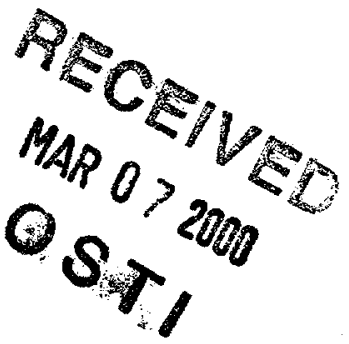

Paper submitted to the MRS Symposium Proceedings "Materials Science of Microelectromechanical Systems (MEMS) Devices II"

*Work supported by the U. S. Department of Energy, BES-Materials Sciences and Office of Transportation Technology, under Contract W-31-109-ENG-38. 


\section{DISCLAIMER}

This report was prepared as an account of work sponsored by an agency of the United States Government. Neither the United States Government nor any agency thereof, nor any of their employees, make any warranty, express or implied, or assumes any legal liability or responsibility for the accuracy, completeness, or usefulness of any information, apparatus, product, or process disclosed, or represents that its use would not infringe privately owned rights. Reference herein to any specific commercial product, process, or service by trade name, trademark, manufacturer, or otherwise does not necessarily constitute or imply its endorsement, recommendation, or favoring by the United States Government or any agency thereof. The views and opinions of authors expressed herein do not necessarily state or reflect those of the United States Government or any agency thereof. 


\section{DISCLAIMER}

Portions of this document may be illegible in electronic image products. Images are produced from the best available original document. 


\title{
TWO- AND THREE-DIMENSIONAL ULTRANANOCRYSTALLINE DIAMOND (UNCD) STRUCTURES FOR A HIGH RESOLUTION DIAMOND. BASED MEMS TECHNOLOGY
}

\author{
O. AUCIELLO ${ }^{1}$, A.R. KRAUSS ${ }^{2}$, D.M. GRUEN ${ }^{2}$, E.M. MEYER ${ }^{3}$, H.G. BUSMANN ${ }^{4}$, \\ J. TUCEK, ${ }^{2}$ A. SUMANT ${ }^{2}$, A. JAYATISSA ${ }^{2}$, N. MOLDOVAN ${ }^{5}$, D. C. MANCINI ${ }^{5}$, \\ AND M. N. GARDOS 6 \\ ${ }^{1}$ Argonne National Laboratory, Materials Science Division, Argonne, IL 60439 \\ ${ }^{2}$ Argonne National Laboratory, Materials Science and Chemistry Divisions, Argonne, \\ IL 604439 \\ ${ }^{3}$ Institute for Microsensors, Actuators, and Systems (IMSAS), University of Bremen, Bremen, \\ ${ }^{4}$ Fraunhofer Institute for Applied Materials Science, (IFAM), Bremen \\ ${ }^{5}$ Experimental Facilities Division, Argonne National Laboratory, Argonne, Illinois 60439 \\ ${ }^{6}$ M. N. Gardos, Raytheon Systems Company, 2000 El Segundo, CA 90245
}

\begin{abstract}
Silicon is currently the most commonly used material for the fabrication of microelectromechanical systems (MEMS). However, silicon-based MEMS will not be suitable for long-endurance devices involving components rotating at high speed, where friction and wear need to be minimized, components such as 2-D cantilevers that may be subjected to very large flexural displacements, where stiction is a problem, or components that will be exposed to corrosive environments. The mechanical, thermal, chemical, and tribological properties of diamond make it an ideal material for the fabrication of long-endurance MEMS components. Cost-effective fabrication of these components could in principle be achieved by coating $\mathrm{Si}$ with diamond films and using conventional lithographic patterning methods in conjunction with e. g. sacrificial $\mathrm{Ti}$ or $\mathrm{SiO}_{2}$ layers. However, diamond coatings grown by conventional chemical vapor deposition (CVD) methods exhibit a coarse-grained structure that prevents highresolution patterning, or a fine-grained microstructure with a significant amount of intergranular non-diamond carbon. We demonstrate here the fabrication of 2-D and 3-D phasepure ultrananocrystalline diamond (UNCD) MEMS components by coating Si with UNCD films, coupled with lithographic patterning methods involving sacrificial release layers. UNCD films are grown by microwave plasma CVD using $\mathrm{C}_{60}-\mathrm{Ar}$ or $\mathrm{CH}_{4}-\mathrm{Ar}$ gas mixtures, which result in films that have 3-5 nm grain size, are 10-20 times smoother than conventionally grown diamond films, are extremely resistant to corrosive environments, and are predicted to have a brittle fracture strength similar to that of single crystal diamond.
\end{abstract}

\section{INTRODUCTION}

Research is being performed to develop materials and fabrication strategies to produce microelectromechanical systems (MEMS) for various technological applications. Many of these systems are currently fabricated entirely on silicon substrates using microcircuit fabrication technology. However, the mechanical properties of Si are very poor ${ }^{1,2}$, such that Si-based MEMS are unable to drive power-trains under realistic loads, and exhibit high energy loss due to high friction. In addition, Si-based MEMS devices that involve extensive rolling or sliding motion typically wear out in a very short time ${ }^{1}$. Clearly, Si is not an appropriate material for some MEMS devices, even for room temperature applications. Si MEMS components coated with $\mathrm{Si}_{3} \mathrm{~N}_{4}$ or $\mathrm{SiC}$ exhibit better behavior than pure $\mathrm{Si}$ in room-temperature MEMS applications, but they also have materials and fabrication limitations ${ }^{3-5}$.

Some of the projected MEMS applications for energy production require operation at elevated temperatures in corrosive or oxidizing environments ${ }^{4}$. Materials required for MEMS operating in harsh environments fall into two categories that can be designated as class 1 or class 2. Only high temperature alloys or ceramics (e.g., $\mathrm{Si}_{3} \mathrm{~N}_{4}$ and $\mathrm{SiC}$ ) that develop protective, chemically stable oxygen diffusion barriers (oxide layers) may be reasonable candidates for 
class 1 materials ${ }^{6.7}$. Class 2 materials include those suitable for MEMS components that are exposed to tribo-thermo-oxidative degradation. Conventional MEMS materials such as Si and metals (e.g. Ni) used in LIGA processes are especially vulnerable to this degradation mode. Class 2 tribomaterials must exhibit high hardness and fracture toughness at relatively high temperatures, and since it is not possible to use separate liquid lubricants on the MEMS scale, the sliding/rolling interfaces must somehow be rendered self-lubricating. Diamond exhibits self-lubrication as a result of either hydrogen or oxygen termination layers, depending on the temperature and gas environment, and it appears to perform better than $\mathrm{SiC}$ in low oxygen partial pressure (up to several Torr) environments ${ }^{8}$ at temperatures up to $\sim 900{ }^{\circ} \mathrm{C}$. In addition, diamond is a superhard material of high mechanical strength, low friction coefficient, and outstanding thermal stability. The projected wear life of diamond MEMS components is 10,000 times greater than that of $\mathrm{Si}^{9}$.

In spite of all the desirable properties of diamond, being the hardest-known material, it is notoriously difficult to fabricate in bulk form. Therefore, various groups are exploring the use of diamond coatings to produce Si-MEMS devices capable of performing useful work. A large number of MEMS structures have been reported ${ }^{10-17}$, using conventional $\mathrm{CH}_{4} /(98-99 \%) \mathrm{H}_{2}$ plasma chemistry ${ }^{18}$ to grow diamond films by chemical vapor deposition (CVD) on Si and $\mathrm{SiO}_{2}$ patterned structures. The main limitations of the conventional CVD diamond coatings are roughness $(\geq 0.5 \mu \mathrm{m})$ and large grain size $(\geq 1 \mu \mathrm{m})$, which limits the feature resolution.

Most problems related to the integration of diamond with MEMS can be overcome using a new synthesis technique developed at Argonne National Laboratory (ANL) that produces phase-pure ultrananocrystalline diamond (UNCD) with morphological, tribological and mechanical properties that are ideally suited for MEMS applications. UNCD films are distinguished from other micro and nanocrystalline diamond and diamond-like carbon films by their grain size, $\mathrm{sp}^{3} / \mathrm{sp}^{2}$ bond content and surface roughness (see Table 1). We demonstrate here that the UNCD coatings can be used in the development of a new diamond-based MEMS technology.

Table I: Distinguishing Characteristics of Diamond and Diamond-Like Carbon Films

\begin{tabular}{|c|c|c|c|c|c|}
\hline & \multirow{2}{*}{$\begin{array}{l}\text { Micro- } \\
\text { crystalline } \\
\text { diamond } \\
\text { (MCD) }\end{array}$} & \multirow{2}{*}{$\begin{array}{l}\text { Nano-crystalline } \\
\text { diamond } \\
\text { (NCD) }\end{array}$} & \multirow{2}{*}{$\begin{array}{l}\text { Ultranano- } \\
\text { crystalline } \\
\text { diamond } \\
\text { (UNCD) }\end{array}$} & \multicolumn{2}{|c|}{$\begin{array}{l}\text { Diamond-Like Carbon } \\
\text { (DLC) }\end{array}$} \\
\hline & & & & ta-C & ta-H:C \\
\hline $\begin{array}{l}\text { Growth } \\
\text { Species }\end{array}$ & $\begin{array}{l}\mathrm{CH}_{3}{ }^{*} \\
\left(\mathbf{H}^{0}\right)\end{array}$ & $\begin{array}{l}\mathrm{CH}_{3}{ }^{*} \\
\left(\mathbf{H}^{\circ}\right) \\
\end{array}$ & $\overline{C_{2}}$ & $\mathbf{C}$ & $\bar{C}$ \\
\hline Cristallinity & $\begin{array}{l}\text { Columnar } \\
\text { (100) or (111) } \\
\text { Diamond }\end{array}$ & $\begin{array}{l}\text { Mixed diamond } \\
\& \text { non-diamond } \\
\text { Phases }\end{array}$ & $\begin{array}{l}\text { Equiaxed } \\
\text { diamond }\end{array}$ & $\begin{array}{l}\text { Mixed diamond } \\
\text { amorphous } \\
\text { phases }\end{array}$ & Amorphous \\
\hline Grain Size & $\sim 0.5-10 \mu \mathrm{m}$ & $50-100 \mathrm{~nm}$ & $2-5 \mathrm{~nm}$ & variable & $\overline{\mathrm{NA}}$ \\
\hline $\begin{array}{l}\text { Surface } \\
\text { Roughness }\end{array}$ & $400 \mathrm{~nm}-1 \mu \mathrm{m}$ & $50-100 \mathrm{~nm} \mathrm{rms}$ & $20-40 \mathrm{~nm} \mathrm{rms}$ & $5-100 \mathrm{~nm} \mathrm{rms}$ & $1-30 \mathrm{~nm} \mathrm{rms}$ \\
\hline $\begin{array}{l}\text { Electronic } \\
\text { Bonding }\end{array}$ & $\mathrm{sp}^{3}$ & $\begin{array}{l}\text { up to } 50 \% \mathrm{sp}^{2} \\
\text { (second phase) }\end{array}$ & $\begin{array}{c}2-5 \% \mathrm{sp}^{2} \\
\text { (grain bound.) }\end{array}$ & up to $80 \% \mathrm{sp}^{3}$ & $\operatorname{up}_{\mathrm{sp}^{3}}$ to $\sim 40 \%$ \\
\hline $\begin{array}{l}\text { Hydrogen } \\
\text { Content }\end{array}$ & $<1 \%$ & $<1 \%$ & $<1 \%$ & $<1 \%$ & $15-60 \%$ \\
\hline
\end{tabular}

\section{SYNTHESIS AND CHARACTERIZATION OF UNCD COATINGS}

The UNCD growth process involves either $\mathrm{C}_{60}$ or $\mathrm{CH}_{4}$ precursors in an argon microwave plasma ${ }^{19}$ with little or no added $\mathrm{H}_{2}^{20}$. In the absence of significant quantities of $\mathrm{H}_{2}$, the carbon dimer, $\mathrm{C}_{2}$, is the dominant carbon species rather than $\mathrm{CH}_{3}{ }^{21}$. It has been shown theoretically ${ }^{22}$ that $\mathrm{C}_{2}$ is able to insert directly into the diamond lattice without the assistance of hydrogen 
abstraction reactions. Experimentally, it has been shown that there is insufficient $\mathrm{CH}_{3}$ present in the plasma ${ }^{22}$ to account for the observed growth rate, which is directly proportional to the $\mathrm{C}_{2}$ plasma concentration ${ }^{23}$. In the relative absence of atomic hydrogen, renucleation occurs rapidly, and the nascent nucleation sites are able to grow into diamond crystals with low probability of regasification. However, the high renucleation rate limits the size of the grains to $3-5 \mathrm{~nm}$. In this size range ${ }^{24}$, diamond is the thermodynamically stable phase, and there is therefore no tendency to form graphitic impurities ${ }^{22}$. X-ray photoabsorption spectroscopy ${ }^{25}$, UV excitation Raman spectroscopy ${ }^{26}$, and EELS ${ }^{27}$ show that the electronic bonding character is almost entirely $\mathrm{sp}^{3}$. High resolution TEM studies ${ }^{26}$ reveal that UNCD films are formed by equiaxed nanocrystalline grains with atomically abrupt grain boundaries and no trace of intergranular non-diamond phases. These films exhibit a friction coefficient equal to that of single crystal diamond ${ }^{28}(\sim 0.04)$, excellent tribological properties, resistance to chemical attack, and extreme smoothness ( $20-40 \mathrm{~nm} \mathrm{rms})$, making them ideal for integration into MEMS devices.

\section{FABRICATION OF UNCD-MEMS COMPONENTS}

\subsection{UNCD-Based Shafts for Rotating MEMS Components}

The fabrication of MEMS devices with rotating components will require the integration of the rotating part (e.g., gear, wheel, or turbine) with a supporting shaft. The interaction of the wheel hub with the shaft can result in extreme wear of one or both components rendering the MEMS device useless after a short period of operation as shown for $\mathrm{Si}$ pinwheels ${ }^{2}$. This problem can be overcome by using shafts and rotating components coated with UNCD films. Therefore, as a first step in the demonstration of UNCD-based MEMS rotating devices, we have demonstrated the fabrication of UNCD shafts. For this purpose, we fabricated Si post arrays of different diameter, height, and spacing using conventional lithographic methods in conjunction with reactive ion etching. Fig. 1(a) shows an example of such posts fabricated to near-net diameter. The posts were subsequently coated with a $1 \mu \mathrm{m}$ thick conformal, smooth UNCD film (Fig. 1(b)). The small irregularities on the surface of the as-deposited UNCD layer (Fig. 1(b)) may serve to reduce the contact area, and therefore the frictional force. Using the same UNCD-coated Si posts, we demonstrated the feasibility of fabricating hollow cylindrical structures. For this purpose, we irradiated the posts with a collimated ion beam $\left(2.1 \mathrm{~mA} / \mathrm{cm}^{2}\right.$, $500 \mathrm{eV} \mathrm{Kr}$ ) impacting normally to the substrate. This resulted in the physical removal of the UNCD coating on the top of the posts. Subsequently, we performed selective chemical etching of the exposed $\mathrm{Si}$ core using a $3: 1 \mathrm{HNO}_{3} / \mathrm{HF}$ solution, resulting in the freestanding UNCD cylindrical structure shown in Fig. 1 (c). During the ion irradiation of the UNCD posts, $\mathrm{Kr}^{+}$ ions impacting on the side of the posts at a grazing incidence angle resulted in ion bombardment-induced polishing of the cylinder walls (compare Figs. 1(b) and 1(c)).

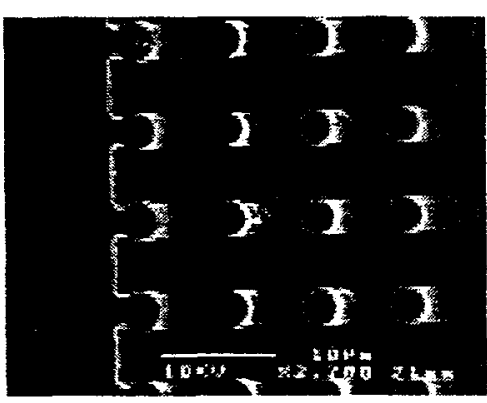

(a)

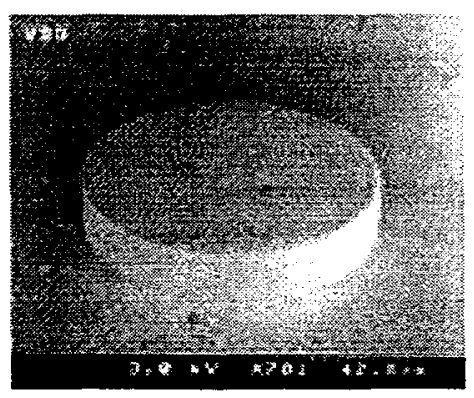

(b)

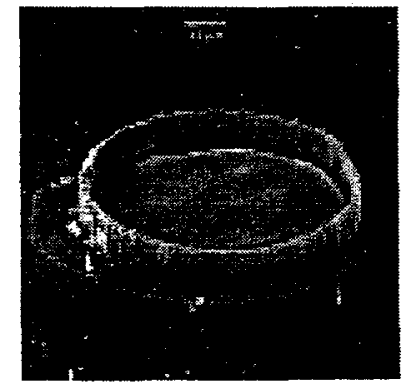

(c)

FIGURE 1. SEM micrographs of: (a) array of Si posts; (b) magnified view of a Si post with as-deposited $1 \mu \mathrm{m}$ thick UNCD layer; and (c) magnified view of a UNCD-coated Si post after ion beam polishing of the side-wall and selective reactive ion etching of the Si core, to produce a UNCD free-standing hollow cylinder. 
We studied the effect of ion beam polishing on possible surface graphitization by comparing microcrystalline diamond films with grain size $>1 \mu \mathrm{m}$ in diameter and UNCD films on planar Si substrates, using a $500 \mathrm{eV} \mathrm{Kr}{ }^{+}, 20 \mathrm{~mA}, 3 \mathrm{~cm}$ diameter ion beam impacting at $20-25^{\circ}$ with respect to the surface. Raman analysis of the microcrystalline diamond film revealed a substantial increase in the $\mathrm{sp}^{2}$ peak, indicating that ion bombardment of large grain diamond films results in extensive graphitization ${ }^{29}$, although no graphitization was observed in the UNCD sample. The reason for the lack of observable graphitization in UNCD may be related to the fact that for grains $<5 \mu \mathrm{m}$ in diameter, diamond is the thermodynamically stable phase of $\operatorname{carbon}^{30}$, although more comprehensive studies are required. The ion beam polishing reduced the rms roughness of the as-deposited UNCD films from $(\sim 30-40 \mathrm{~nm})$ to $\sim 17 \mathrm{~nm}$, as determined by AFM measurements. The parameters for ion beam polishing have not been optimized, and it may be possible to further reduce the surface roughness by changing the kinetic energy and angle of ion beam incidence.

\subsection{Fabrication of 2-D UNCD-MEMS Structures}

The fabrication of 2-D MEMS structures based on diamond-coated Si substrates requires lithography and chemical and/or reactive ion etching steps. In addition, it is frequently necessary to grow diamond films on sacrificial layers such as $\mathrm{SiO}_{2}$. It is very difficult to grow diamond films on $\mathrm{SiO}_{2}$ using conventional CVD growth methods, involving $\mathrm{CH}_{3}$-based precursor insertion. However the $\mathrm{C}_{2}$ dimer growth species in the UNCD process can insert directly into either the $\mathrm{Si}$ or $\mathrm{SiO}_{2}$ surface. The fundamental reason for the ability to grow UNCD films on $\mathrm{SiO}_{2}$, using the $\mathrm{C}_{2}$-based nucleation and growth mechanism characteristic of the UNCD film growth process, is contained in the following surface chemical reaction:

$$
\mathrm{SiO}_{2(\mathrm{~s})}+\mathrm{C}_{2(\mathrm{~g})} \rightarrow \mathrm{SiC}_{(\mathrm{s})}+\mathrm{CO}_{2(\mathrm{~g})}-\mathrm{F} \sim-100 \mathrm{Kcal}
$$

The driving force for the reaction shown above is in part related to the high energy of formation of the $\mathrm{C}_{2}$ molecule, which helps to overcome the intrinsic stability of $\mathrm{SiO}_{2}$. The presumed formation of a layer of $\mathrm{SiC}$ on the $\mathrm{SiO}_{2}$ surface can provide a surface on which diamond grains nucleate easily.

A possible method for the fabrication of a wide range of 2.5 dimensional "Manhattantype" UNCD structures was demonstrated using the following steps: (1) UNCD deposition onto a $\mathrm{SiO}_{2}$ release layer; (2) PECVD deposition of an oxide (1 $\mu \mathrm{m}$ thick) as a hard mask material, (3) photolithographic patterning; (4) RF dry etching of the hard mask $\left(\mathrm{CF}_{4}\right.$ flow $=16$ $\mathrm{sccm}, \mathrm{CHF}_{3}$ flow $=8 \mathrm{sccm}$, coil power $=800 \mathrm{~W}$, platen power $=70 \mathrm{~W}$, chamber pressure $=3$ mTorr, etching time $=6 \mathrm{~min}) ;.(5)$ patterning of the diamond in a directed oxygen plasma (Argon flow $=30 \mathrm{sccm}$, oxygen flow $=30 \mathrm{sccm}$, coil power $=800 \mathrm{~W}$, platen power $=200 \mathrm{~W}$, chamber pressure $=5 \mathrm{~m}$ Torr, etching time $=19 \mathrm{~min}$.); (6) removal of the oxide hard mask and sacrificial $\mathrm{SiO}_{2}$ layer by $\mathrm{HF}$ etching. Fig. 2(a) shows two diamond cantilever structures facing each other. They were deposited on a $\mathrm{SiO}_{2}$ release layer. The cantilevers have a series of holes to allow the HF etchant access to the sacrificial $\mathrm{SiO}_{2}$ layer in order to free the cantilevers from the substrate. The large corner pads in Fig. 2 do not have these holes, and because of their relatively large size, they remain attached to the substrate.

Differential motion of the four pads at the corners of the device is amplified by the offset support points along the arms of the cantilevers, and the device functions as a MEMS strain gauge. Figs. 2 (b) and (c) show increasingly magnified views of the end of the UNCD cantilever structures, still unreleased from the $\mathrm{Si}$ substrate. The structures on the crossbar represent the scale of a vernier readout for a precise measurement of very small differential motion. 


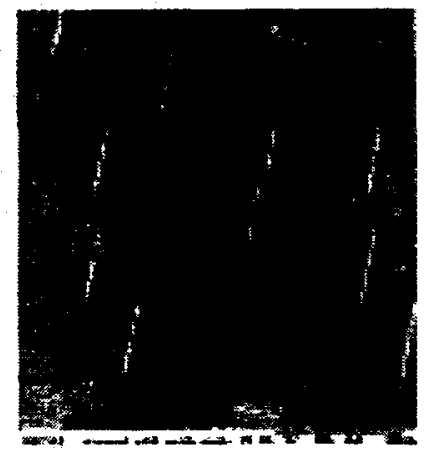

(a)

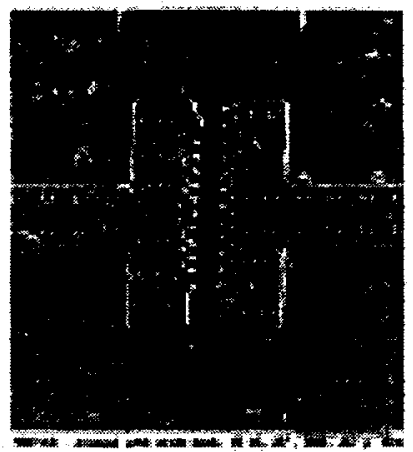

(b)

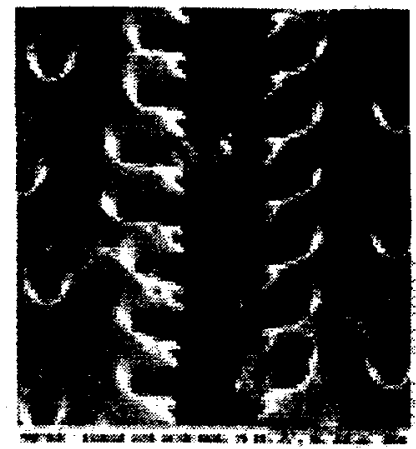

(c)

FIGURE 2. SEM showing the morphological characteristics of UNCD-Si coated cantilevertype structures. Figs. 2 (b-c) show views of the same structure at increasingly higher magnification.

Figure 3 (a) shows a released UNCD cantilever structure, which exhibits surprisingly little vertical curl, indicating that UNCD, unlike microcrystalline diamond films has extremely low residual stress. Previous attempts at producing such diamond structures were limited both by intrinsic film stress and by the attainable feature resolution, which was limited by the diamond grain size (typically $\sim 1 \mu \mathrm{m}$, see Fig. 3(b)). However, the feature size of the vernier scale in Fig. 2 is $\sim 100 \mathrm{~nm}$.

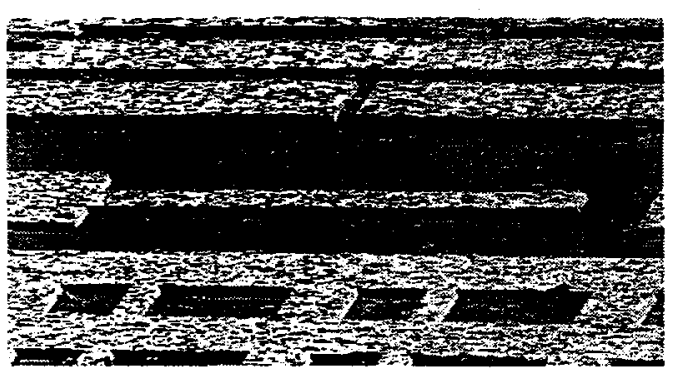

(a)

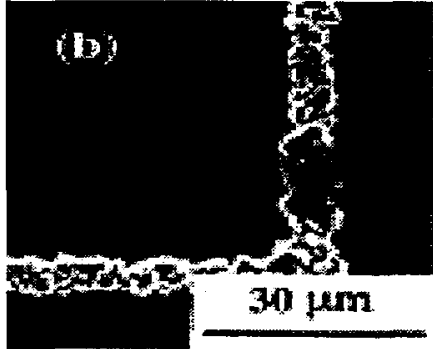

(b)

FIGURE 3. (a) SEM micrograph of UNCD released cantilevers. (b) SEM micrograph of a selectively grown diamond film on $\mathrm{Si}$, using conventional $\mathrm{CVD}$, which shows the limitations of this method (specifically, the large grain size of conventional CVD-diamond) for the fabrication of high-resolution MEMS structures.

The successful fabrication of the cantilevered structures shown in Figs. 2 and 3 (a) demonstrates that it is possible to produce stable 2-dimensional free-standing UNCD structures using modified Si fabrication technologies.

\section{CONCLUSIONS}

Silicon-based MEMS will not be suitable for long-endurance devices involving extensive rolling and/or sliding contact or components that will be exposed to corrosive environments. The initial results presented in this paper demonstrate that UNCD-coated Si or UNCD freestanding structures may provide a solution to tribological and mechanical properties limitations of Si-based MEMS devices. We have demonstrated the use of phase-pure UNCD films for the fabrication of MEMS components, using lithographic patterning and etching to fabricate a two-dimensional cantilevered UNCD-MEMS strain gauge with $\sim 100 \mathrm{~nm}$ feature size. Prior similar diamond structures were limited in resolution by the grain size (typically $\sim 1$ $\mu \mathrm{m}$ ) of the conventionally grown diamond layer. We coated Si posts with conformal UNCD films to produce shafts for rotor and gear support. The ion beam etching that was used to remove the diamond coating from the top of the posts also resulted in a polishing of the sides, reducing rms roughness from $30-40 \mathrm{~nm}$ to $\sim 17 \mathrm{~nm}$. In addition, we demonstrated the 
feasibility of fabricating hollow cylindrical structures by reactive ion etching of the Si core. The ability to produce 3D diamond structures represents a break-through in nanoscale fabrication technology.

\section{ACKNOWLEDGMENTS}

The work was funded by the DOE Office of BES under contract W-31-109-ENG-38.

\section{REFERENCES}

1. A.P. Lee, A.P. Pisano, and M.G. Lim, Mat. Res. Soc. Symp. Proc. Vol. 276, 67 (1992).

2. K.J. Gabriel, F. Behi, R. Mahadevan, and M. Mehregany; Sensors and Actuators A21-A23, 184 (1990).

3. M. Neuberger, Mat. Res.Bull. vol 4, 365 (1969).

4. S.M. Spearing and K.S. Chen, in "Tribology Issues and Opportunities in MEMS", edited by B. Bhushan, Kluwer Academic Publisher, The Netherlands (1998) p. 95.

5. Z. Rymuza, Z. Kusznierewicz, M. Misiak, K. Schmidt-Szalowski, Z. Rzanek-Boroch, and J. Sentek, "Tribology Issues and Opportunities in MEMS", edited by B. Bhushan, Kluwer Academic Publisher, The Netherlands (1998) p 579.

6. M.N. Gardos, Tribol. Trans. 31, 427(1988); Tribol. Trans. 32, 30 (1989).

7. M.N. Gardos, H.S. Hong and W.O. Winer; Tribol. Trans. 32, 209 (1990).

8. M.N. Gardos (private communication, 1999).

9. M. N.Gardos in Tribology Issues and Opportunities in MEMS, p. 341, B. Bhushan ed., Kluwer, 1998; Surface and Coatings Technology 113, 183 (1999).

10. J.L. Davidson, R. Ramesham, and C. Ellis, J. Electrochem. Soc. 137, 3206 (1990).

11. M. Aslam, G.S. Yang, and A. Masood, Sensors and Actuators A45, 131 (1994).

12. D.R. Wur, J.L. Davidson, W.P. Kang, and D.L. Kinser, J. Micromech. Syst. 4, 34 (1995).

13. O. Dorsch, K. Holzner, M. Werner, E.. Obermeir, R.E. Harper, C. Johnston, P.R. Chalker, and I.M. Buckley-Golder, Diamond Relat. Mater. 2, 1096 (1993).

14. G. Zaho, E.M. Charlson, E.J. Charlson, T. Stacey, J. Meese, G. Popovici, and M. G. Prelas, J. Appl. Phys. 73, 1832 (1993).

15. S. Moller, E. Obermeir, and J. Lin, Sensor and Actuators B: Chemical 25, 343 (1995).

16. J.L. Davidson and W.P. Wang, Mater. Res. Soc Symp. Proc. 416, 397 (1996).

17. G.S. Yang and D.M. Aslam, IEEE Electron. Dev. Lett. 17, 250 (1996).

18. S. J. Harris and D. G. Goodwin, J. Phys. Chem 97, 23 (1993).

19. D. M. Gruen, S. Liu, A. R. Krauss, J. Luo, and X. Pan, Appl. Phys. Lett. 64, 1502 (1994).

20. D. M. Gruen, S. Liu, A. R. Krauss and X. Pan, J. Appl. Phys. 75, 1758 (1994). R. Csencsits, D. M. Gruen, A. R. Krauss and C. Zuiker, Mat. Res. Soc. Symp. Proc. 403, 291 (1996).

21. A. N. Goyette, J. E. Lawler, L. W. Anderson, D. M.Gruen, T. G. McCauley, D. Zhou, and A. R. Krauss, J. Phys. D: App. Phys. 31, 1975-1986 (1998)

22. P. C. Redfern, D. A. Horner, L. A. Curtiss and D. M. Gruen, J. Phys. Chem. 100, 11654 (1996).

23. D. M. Gruen, C. D. Zuiker, A. R. Krauss, and X. Pan, J. Vac. Sci. Technol. A13, 1628 (1995).

24. J. A. Nuth, Nature, 329, 589 (1987)

25. C. D. Zuiker, A. R. Krauss, D. M. Gruen, J. A. Carlisle, L. J. Terminello, S. A. Asher, and R. W. Bormett. Mat. Res. Soc. Proc. 437, 211 (1996).

26. R. Csencsits, C. D. Zuiker, D. M. Gruen, A. R. Krauss, Solid State Phenom. 51-52, 261(1996).

27. D. M. Gruen, S. Liu, A. R. Krauss, J. Luo and X. Pan, Appl. Phys. Lett. 64, 1502 (1994)

28. A. Erdemir, C. Bindal, G. R. Fenske, C. Zuiker, R. Cesncsits, A. R. Krauss and D. M. Gruen, Diamond Films and Technology 6, 31 (1996)

29. O. Auciello, A.R. Krauss, D.M. Gruen, E.M. Meyer, H.G. Busmann, J. Tucek, A. Sumant, A. Jayatissa, M. Q. Ding, N. Moldovan, D. C. Mancini, and M. N. Gardos, Jour. of Microelectromechanical Systems (in press, 1999).

30. J.A. Nuth, Nature vol. 329, 589 (1997). 